\title{
The Construction of Gender in Mid-Century British Social Anthropology
}

\author{
G.V. Loewen \\ Department of Sociology,STM College, The University of Saskatchewan, 1437 College Drive, Saskatoon, SK Canada
}

\begin{abstract}
The historical construction and fieldwork exploits of the B.S.A. are well known. Here, an exploration of the position or constitution of what is perhaps a more contemporary construction, that of gender, within a set of key texts from the period of 1940-1970. Such an exploration presents at first no great difficulty. Whether male or female the authorship of the objects described, that is, ethnographically or historically known societies, is taken for granted to be neutral, which is to say the same thing as being male. The male in all societies was the giver of important information, the female a given. Yet things are more subtle than they at first appear, and the politics and the science of the sources of such a construction can be clarified by understanding such texts within the apparatus of Western kin structures that at the time were undergoing serious challenges.
\end{abstract}

Keywords Gender, Kinship, Social Anthropology, Politics, Science

\section{Introduction}

It would seem quite impossible that anyone would recognize as kinsmen all of these; it was a theoretical construction of the lawyers, not something used in their practice. ([14]: 68).

The beautiful irony of this quote, in which RadcliffeBrown discusses the pragmatic disadvantages in the cognatic system of the Teutonic ancestors to Northern Europeans, unknowingly speaks truth of the system their successors constructed to make sense of other people's kinship. Figures such as Maine and Bachofen imagined systems to describe the social relations of humanity, which later began to have more than mere descriptive powers ascribed to them - they could also explain the nature of human relations. If students would merely fill in global and cross-cultural detail, one would have a complete comparative explanation for human difference and distance. For over a century, with some major exceptions, this has been the goal of anthropology as a whole, and British social anthropology in particular. The historical construction and fieldwork exploits of the B.S.A. are well known. We wish to explore the position or constitution of what is perhaps a more contemporary construction, that of gender, within a set of key texts from the period of 1940-1970. Such an exploration presents at first no great difficulty. Gender issues were ignored in this period by the authors in question. Whether male or female the authorship of the objects described, that is, ethnographically or histori-

* Corresponding author:

gloewen@stmcollege.ca (G.V. Loewen)

Published online at http://journal.sapub.org/sociology

Copyright (C) 2011 Scientific \& Academic Publishing. All Rights Reserved cally known societies, is taken for granted to be neutral, which is to say the same thing as being male. The male in all societies was the giver of important information, the female a given.

\section{Objectives}

Yet if constituted along these well-beaten paths, the examination of gender and the how and why of its position or lack thereof will be superficial. Instead, we must ask ourselves some different, and perhaps ultimately more illuminating questions. It is also not enough to maintain the tired saying 'the author is dead', allowing free reign of interpretations and storytelling. Alternatively, we need to construct an author capable of infusing gender into such texts, to see if they can at once hold such a conception in a meaningful manner, and in simultaneity give forth the essence of their historical neuter. We must ask of the texts at least the following questions: What marks exist within these texts that may act as a trace for an archaeology of gender?Are there certain characteristics that are present, that given our contemporaneity, are read differently than before? If we cannot say what the authors read into such work, we know historically what positions or non-positions were extant during the period in question. What was the nature of the dialogue between texts and readers within that period - their assumptions, their expectations, their circumscribed necessities? In short, how do concepts become vital, how do they disintegrate, how are they resurrected?

Most importantly, we must ask whether or not it is meaningful to create gender in such a body of work, even if such work perhaps constitutes a consistent corpus? If gender 
is found not to exist in any identifiable form, what is the justification for reviewing historical documents in this light? Can 'gender' indeed be isolated from other assumed and expected constructions such as the 'economic', the 'politic', the 'aesthetic', or the 'ethic' of the anthropologist's societies or their objects? Probably not. It seems to us that the culture of the constructor exercises far more influence over any work that comes out of fieldwork than does the culture that the anthropologist ostensibly is studying. We must therefore look to European constructions of 'gender', both synchronically and diachronically to ferret out or ferret in gender for these texts.

\section{Methods}

We can begin with Fortes' and Evans-Pritchard's African Political Systems, and move through Radcliffe-Brown's African Systems of Kinship and Marriage, taking with its case many selections reprinted in Jack Goody's 1971 review Kinship, among others. In the isolation of gender throughout these texts we will argue that by direct and indirect analogy students of British social anthropology are a) reflecting then current ideologies and power relations between male and female in Europe (We say 'then' because we do not wish to broach an analysis of the 'now' in this paper, although the argument could more or less be extended up to this point in time), b) expressing a latent nostalgia for those forms of power relations that are seen to be changing even in the period in question, and c) are hence motivated by a powerful necessity to re-construct strategies of kinship and social organization around facets of culture naively placed away from the dangerous influence of 'gender', that is, the 'politic', the 'ethic', the 'aesthetic', and the 'economic'.

We will say that these three strategies constitute the essence of such texts in their relation to a modern conception of what gender is, assuming for academic purposes that our conception is fully viable in an analysis of a just passed discourse.

Within these texts, and let us take for the moment the texts representing the first decade of our period, that of 1940-1950, two axes of traces immediately become apparent. The first axis is one that we may call 'empirical', corresponding to the traces of the 'position' of gender that are indubitably marked by the media in the text itself. These marks are as follows: 1 . the word order in sentences in which there are descriptions related to gender (or 'sex', for the period), 2. the difference in size of the type font in diagrams and narrative when genders are compared or juxtaposed, 3. the use of the male pronoun almost universally within the narrative when the description veers towards 'the natives' point of view, or in the description of genealogies, economic and political relations, and ideological motivations for 'the native's' actions, and not only 'the native's'. Within number three above, there are a multitude of separate instances and circumstances that give us clues as to the 'position' of gender, and a representative sample will be quoted.
The second and more important axis - for a discussion of the first only would have the shallow effect of producing some kind of 'sexism' inherent in the culture of the textproducers or in the societies they studied, or both, and conclude because of this that gender or at least the female gender did exist and was oppressed and ignored, instead of noting that the very possibility of the concept 'gender' was at most only nascent within these texts and our time period - consists of the analogic and associative intentions within the texts themselves, which are not betrayed by 'empirical' marks of black on white, but are not yet deeper or somehow subterranean, below the text. Nor do they constitute an 'unsaid', to be infused hermeneutically with meanings corresponding to our own strategies of discourse - although that may be ultimately what they do, unbeknownst to us. This second axis springs forth autochthonously from the very same black marks on white paper, it just does so in a different manner. This time, the trace is created by the dialogue extant when one observes such texts out of their time, as it were. The response that is made is rife with analogies, associations, experientially driven conflicts of interpretation and ideology, and above all, but occurring somewhat later than the dialogue itself, the infusion of the contemporary strategy into the now contemporary text.

Although both the axes of traces are ultimately hermeneutic in quality and play, one is extant via the structure of the discursive marks, and the second possible because of the conflict of temporal readings. The first axis could easily be replicated in form today; word order, type font, grammar of sex, etc, but the second could never be recreated in as similar a fashion precisely because the mode of dialogue with even similarly constructed texts has shifted. This shift may allow the introduction of the concept 'gender' in the first place, and hence such an examination as ours may be both possible for a discursive interrogation, and necessary for an ideological strategy.

\section{Results}

Let us exemplify the shallow axis first. The word order that is almost always apparent in these texts when gender or 'sex' terminologies are juxtaposed is androcentrically oriented. There are literally hundreds of examples of this: "...men and women captured in battle or enslaved to their own people for some crime." ([15]:94), "... a small boy or girl, usually a maternal grandchild, is chosen to inherit the name of the deceased..." ([15]:98) "...a bow for a man and a girdle for a woman..." ([15]:98), "A number of these mutilated men and women still survive in Bemba country today." ([15]:106), "There are conventional payments considered due to a man who has suffered certain injuries - adultery with his wife, fornication with his daughter..." ([2]:293), "Does a man ever sleep with his sister?" ([11]:55), "Initiation rituals confirms this emancipation of the young man or girl..." ([11]:57), "...the crucial point is obviously the husband's right to determine the residence of the bride." ([16]:278), "...a parental 
family is a household or homestead composed of a man, his wife or wives, and their children." ([16]:279), "The Bemba commoner can inherit a guardian spirit from his father's side as well as his mother's..." ([16]:285), "Persons are cognatic kin or cognates when they are descended from a common ancestor or ancestress counting descent through males and females." ([14]:4), "...when a husband sues for injuries inflicted upon his wife, the child, apprentice, and wife are in fact held to be things." ([14]:12 italics in original), "...those on the 'spear' side (through the father), and those on the 'spindle' side (through the mother)." ([14]:82), Property rights and authority may go from father to son, from mother to daughter..." ([17]:210), "...or a tithe of cattle obtained as compensation by the husband when she has committed adultery." ([17]:238), "Members of that lineage live with their wives and concubines..." ([4]:371) etc. Or when the order is reversed, something else may be going on: "Let us consider the women of the man's own lineage..." ([14]:20), The wife thus passed under the power and authority of her husband..." ([14]:76), "In order to graft themselves on to the tree of this dominant clan the linked families trace their descent through females at the points of the graft as though these women had been men." ([4]:376), "She becomes 'absorbed' into her husband's lineage." ([7]:242), "...it is where each wife is the center of a separate estate within her husband's property, in house-property systems, that women are accused of this inherent evil." ([7]:243).

The word order, of which there are many more examples, is superficially important because it betrays its message in a literal sense, as well as one more 'underlying'. The literality of the 'observed facts' of female dependence, lack of authority, position as chattel or property, seat of evil, possession, illegitimacy or illegality, receptacle of sexuality, reproduction, domesticity, or just plain millstone or yoke around the male does justice to the paradigm of the enthralled women. This paradigm could be used either to attack the organization which promotes such relations, or as an affirmation of that system. The literal acceptance of an observed or constructed state of affairs whether from medieval or modern England, as in Radcliffe-Brown ([14]), or with the Nuer and EvansPritchard, assumes the observed's literacy and does not question it. This is the way it is, for both male and female anthropologist's, and Audrey Richards, the one female in the group, is not seen as making a defined break from this paradigm. It is easily seen that word order betrays other assumptions that become visible within our second axis of interrogation, through analogy.

The difference in size of type font, though a smaller sample, leaves us a trace that can only be defined from the culture of the anthropologist's, for their objects were 'illiterate'. A few examples come from Radcliffe-Brown ([14]:33 and 39) where ego is male and in capitals, on page 52 in both diagram and narrative of the same piece, where females are designated with small letters vs. those of male in capitals, on pages $220,230,235$, and 240 of Richard's ([16]) where the same thing occurs in more detail, or where females are added only to trace the genealogy of males ([4]:379). In describing and diagramming the world, these texts are seen to constitute and re-create relations seen from a male perspective. The man would 'naturally' put himself first, as the center of the social organization. Perhaps we may even question why kinship diagrams are 'ego' centered. Most often ego is male, or else ego 'maleness' acts also for a female ego, hence the often symmetrical or identical relation extant in such diagrams for brother and sister, and the presumed or inflated importance of the 'sibling relation'.

The use of the universal male third person or possessive pronouns further exemplifies gender orientation towards androcentrism, whether the society in question is historic or ethnographic, whatever lineage type or rule of residence it might have. Again there are hundreds of examples, of which these are a representative few: for example, in the description of 'native' life as a male life, or of male natives as predominant or universal actors in their own culture: "He is more than a secular ruler; in that capacity the European government can to a great extent replace him. His credentials are mystical and are derived from antiquity." ([2]:16), "His membership of this group determines his succession to different offices and his status in the community, although in a matrilocal society it only occasionally determines his residence." ([15]:87), "The senior man present claps as each point is made to mark the recognition of the court, and the chief himself finally sums up and gives judgement." ([15]:108), "The tribesmen have a sense of patriotism..." ([3]:278), "A man is only an aristocrat in the one tribe in which his clan is dominant. If he lives in another tribe, he is not an aristocrat there." ([3]:287), "The term gives no indication of the length of time a man spends in his wife's village, or the degree to which he is incorporated with her matrikin, or isolated from his own family." ([16]:279), "Amongst the Ganda 'no man might see his mother-in-law or speak face to face with her'. Amongst the Galla a man must not mention the name of his mother-in-law..." ([14]:55), "He must also state what present he will give to his bride for permitting the physical consummation of marriage..." ([14]:120), and, including our own society: "Though an engagement ring may have considerable value (more than many Africans 'pay' for their wives), the giving of it is not regarded as an economic or at least not as a business transaction. It is symbolic." ([14]:125). It seems if the outright display of possession has been relegated to symbolic status, a mark of our advancement over the 'vulgar' property relations of the 'savage'.

There are also many examples of the use of the androcentric position for theorizing about native contexts: "Throughout this area, at any rate, the rule of residence at marriage seems to me to be the most important index of the husband's status. It also provides a convenient basis for the classification of these different forms of matrilineal family." ([16]:208). The 'matrilineal puzzle' is only mysterious because the male is seen to be placed in a sort of limbo, bereft of some of his omniscience. Accordingly, the investigation and description of matriliny and matrilocality may be seen as 
an effort to reassert male power over both himself and others. The story of matriliny in these texts is one of the heroic journey of the male from the Goshen of bride price and work terms to the promised land of proprietary interest over the wife and family, however incomplete.

Also, both the scientist doing the study and the reader reading the study's results are presumed to be male: "For the scientist engaged in this task, or while he is so engaged, any particular instance of the phenomena in question is only of interest as part of the material that he can use to formulate or test his hypotheses." ([14]:2), "...in reading my description of their political structure, the reader would have to take for granted the network of kinship and affinal ties within a village. I now ask him to remember..." ([4]:360). The fact that most of the students and readers were male only reinforces the androcentrism of which these texts are a direct reflection. Even so, texts are not mere passive voices reflecting a current state of affairs, and this set of documents may be seen as affirming and continuing the solid if not universal dominance of male-centered participant observation fieldwork, theory building in social anthropology, and relations between actors both in the 'object' cultures and the cultures of the European layman and academic alike.

So far it can easily be shown that 'sexism' was inherent in the formulation of these texts, and hence was likely to be instilled in either the anthropological culture or the native culture or both, in a fundamental manner. But in saying this, we are only giving ourselves a refracted and superficial picture of the state of affairs then current. To enable a discussion of the 'position' of gender in 'British' social anthropology from 1940-1970 we must now turn to the second of our axes. As mentioned, axis two enables its trace not from the more obvious and 'empirically' derived marks as in the above, but from the suspicious reading of other marks which occur from the same texts. By looking at these marks in a dialogic and associative way, we are enabled to construct analogies perhaps inherent in their creation that link ethnographic and theoretical statements to their historical milieux. In at least the first decade of the three under examination, what is revealed by this manner of association is a nostalgia for a set of power relations that was historically changing during the period. The nostalgia wishes to take society back to a time where androcentrism could not exist, paradoxically because there was no possibility for anything to which it could be compared, for example: 'sexism', 'gender', or 'the female', or 'a female language'. Thus anthropologists may be seen to be reflecting their own society's latencies by reading their aspirations into ethnographic cultures, and reminiscing about those historically known. Examples will be cited to reference all of these points.

Let us deal first with the nostalgia for 'androcentric' political and social relations: "The policy of Indirect Rule is now generally accepted in British Africa." ([2]:3), "one group... consists of those societies which have centralized authority...in short, a government. The other group...consists of those societies which lack...government..." ([2]:5), "The subordinate chiefs... have an interest greater than any other section of the people in maintaining the kingship. The ideal constitutional pattern remains the valid norm in spite of breaches of its rules." ([2]:13), "Indirect Rule may be regarded as a policy designed to stabilize the new political order, with the native paramount ruler in this dual role, but eliminating the friction it is liable to give rise to." ([2]:15), "The duty of the women to produce children of her lineage is emphasized..." ([16]:277), "A stable marriage for a Bemba is the first step on the road to headmanship." ([16]:287), "The process of change is inevitable. To a very limited extent it can be controlled by the colonial administration, and it is obvious that the effectiveness of any action taken by an administration is dependent on the knowledge they have at their disposal about the native society...a wise anthropologist will not try to tell an administrator what he ought to do; it is his special task to provide scientifically collected and analysed knowledge that the administrator can use if he likes." ([14]:85), and many others.

Nostalgia, and resistance in the face of change at home the emancipation of women politically, economically, and domestically, may be seen to be driving some of these statements. Witness Radcliffe-Brown's auld langsyneover the state of English marriage practices:

We tend, unless we are anthropologists [!], to judge other people's customs by reference to our own. To understand African marriage we must remember that the modern English idea of marriage is recent and decidedly unusual...a married woman may now take property in her own right; she may take employment that has no connection with her family life but takes her away from it. In the marriage ceremony many women now refuse to promise that they will obey their husbands...Yet it is clear that despite all this some people take twentieth-century English marriage as a standard of 'civilized' marriage with which to compare African marriage. ([14]:119,122).

Whereas by cross-cultural implication, modern marriage may be some kind of extreme form, perhaps near the pathological? We can compare the 'friction' in the EvansPritchard ([2]:15) quote as a result of dual roles of the native leaders to the friction resulting in the new dual and conflicting roles of the 'newly emancipated' woman. Without the 'indirect rule' of men over women, we will have a society 'without a government', one given to anarchy and chaos. Males have a 'great interest' in maintaining the 'valid norm' of this constitution (including a monarchy and patriarchy), and 'indirect rule' eases conflict in the 'new order' of changing women's roles. Although the hope for a 'stable marriage' remains, with women given to pregnancy as their main duty in life, change is 'inevitable', and male (anthropologists and others) can only hope their colleagues (in administration and governing roles) will salvage order by listening to the former's insight

After all, a valid and democratically confined political system is what males see in Africa, and can be directly juxtaposed with what males hold dear about their own system. For example, Evans-Pritchard's characterization of the Nuer polity: "Every Nuer, the product of a hard and equalitarian 
upbringing [as on the playing fields of Eton?], deeply democratic, and easily roused to violence, considers himself as good as his neighbor; and families with joint families, whilst co-ordinating their activities with those of their fellow villagers, regulate their affairs as they please." ([2]:294). That is, males regulate their affairs without interference from females, in concert for the common good. The egalitarian and aggressive stance of the family man cannot be questioned; it seems as natural as any physical law. From this indoctrination stem our European societies and perhaps also that of the Nuer, although that may be of lesser importance.

Many other nostalgias that reinforce the androcentric nature of British politics and economics are in evidence - they constitute a lens through which 'African' societies are characterized: "...the government of the African state consists in a balance between power and authority on the one side, and obligation and responsibility on the other. Everyone who holds political office has responsibilities for the public weal corresponding to his rights and privileges." ([2]:12). Here, the ideal system of 'responsible government' is outlined. Whether to do with country or household (as through the Victorian age in Britain and America the household became a microcosm of the state, with paternal leadership and economic responsibility, and female domestic and childrearing responsibility, just as the state had a collective responsibility to produce 'good citizens', akin to the healthy and responsible children emanating from each microcosm) the fading status quo is being rejuvenated.

Again such motifs appear with economics and territorial capitalism: "In the segmentary societies, war is not a matter of one segment enforcing its will on another, but is the way in which segments protect their particular interest, within a field of common interests and values." ([2]:17). This is particularly striking in light of the period before 1940. It seems to claim that while the ideal of imperialist capitalism can be maintained by 'just wars', protecting the individual's or states interests, which other individual states share, the war which had just started was more like one in which 'one state (Nazi Germany) is enforcing its will on another', and hence cannot be justified. Hence, Germany, or women for that matter, as some males still see 'female emancipation' as a war on men or on the 'legitimate' structure of society, cannot have any moral grounds for such actions, although they may have material aspirations: "In political relations consequently, we find two types of interests working conjointly, material interests and moral interests, though they are not separated in this abstract way in native thought." ([2]:20). If the ideal were followed, material and moral gains would go hand in hand. Since morality was a function of androcentrism, any challenge to that morality by change was illegitimate, as if women were suddenly bound and determined to commit social adultery.

At the time, the political and moral order of Europe could have been seen to be in danger of crumbling, so Europeans looked to Africa to construct what Europe itself needed to survive and promptly infused African societies with this model, while castigating anything that undermined it: "The people explain that the royal family were named after the crocodile because 'they are like crocodiles that seize hold of the common people and tear them with them to bits with their teeth'." ([15]:106). This situation can be compared in allegorical or analogical format to the situation in Europe, with chaos between states extant, and domestic subterfuge just over the horizon. The ideal state of country or in home is one that is antithetical to a tyrannical autocracy. European democracy is set against European fascism, European family types are set against the paradoxically more 'democratic' anarchy of emancipation. It must be remembered that democracy and morality were purely male constructs; witness the reaction and resistance to the sufferance movement in Europe, and the continued resistance to women academics, of which Richards was one early but perhaps too 'traditional' example.

The political and moral order of European family life had moved from unrestrained physical violence directed against women to that of economic violence. This too is mirrored in colonial native relations, where wars of subjugation had given way to materialist reward and punishment, to keep the natives in line: "Older natives seemed to me to comment most upon the ferocity of the Government officials, and the younger to speak of the wealth of the Administration." ([15]:114:note2). The state of pre-W.W. 1 affairs in Europe, as well as the in the era of the cold-war is seen as the universal basis for human relations, and relations between the sexes: "In all the societies which immediately preceded our own and which still surround us, and even in many usages of popular morality, there is no middle path. There is either complete trust or complete mistrust. One lays down one's arms, renounces magic, and gives everything away, from casual hospitality to one's daughter or [even!] one's property." (Mauss:1925:138, in [11]:53).

The exotic of the female is celebrated as an object to be acquired, as opposed to domestic boredom: "Sexual life would not have become what it is. It would have a less personal character, and would leave less room for the free play of the imagination, dreams and the spontaneities of desire...full of devouring passions, Prince Charmings and Sleeping Beauties, shy heroines and triumphant lovers." ([11]:58-9). The androcentric fantasy of sexual exploit is here made universal, and gender can play no part in it. Nor can female fantasy, especially in a language by and for females, play a role. Perhaps such sexual fantasizing and celebrating, as both a means of production of more property (children) and of total control of that already present, would never occur in a gender specific or gender neutral language and mythos.

If one is to maintain a seen to be threatened system, one needs to be able to describe that system in a detailed manner. This may be why this set of texts stresses the import of using scientific processes and terminology. This way, change can be controlled through the harnessing of that which might be changed if left undescribed or unapprehended by an andro- 
centric science: "Each essay is a condensation of a detailed study...undertaken in recent years by the most advanced methods of fieldwork by students trained in anthropological theory." ([2]:3), "Without classification there can be no science" ([14]:2), "Some more complex and systematic classification is needed to represent the facts as they are." ([14]:23), "Such exceptions call for explanations." ([14]:27), "...we should seek some theoretical explanation." ([14]:33), "If these [technical terms] seem to some readers somewhat barbarous it must be remembered that some technical terms are needed for concise description, and have to be invented." ([14]:40), "...but in the comparative study of social systems exceptions and apparent anomalies are of great theoretical importance." ([14]:69), and "We cannot regard as worthy of serious consideration any theory or explanation that does not deal with both of them." ([14]:56) Here he is referring to the so-called joking and avoidance behaviour, both extant and mythologized in European culture.

Another manner in which the moral order of legitimate relations between male and female is threatened is by female bonding. This may be seen to be rejected, through the eliding of resistance through 'observed' native systems: "The Lozi object to marriage with even a classificatory 'sister' of the wife, and say that the competition and rivalry between cowives is likely to destroy the relationship that ought to exist between sisters." ([14]:64). Translated back into the European sphere: that rivalry between men and women outside of the home endangers men's capacity for providing for a stable household, and injures that household's productive responsibility by a women's irresponsible absence - in fact, the partners becoming two husbands, rather than one active worker, the male, and one passive affirmer, the female. This moral and domestic requirement for females is further stressed through a nostalgic analogy: "An Ancestress is remembered by the number of children she bore..." ([16]: 223).

At best, women can be seen as like men, but can never, or should never, challenge the authority that is part of the essence of maleness: "The real 'bull' of the village is, however, Cam's mother Nyagen, and the village is often spoken of as ciengNyagen. She has what amounts to the honorary status of a man..." ([4]:374). In fact, only through the undermining of the marriage bond are women implicitly able to free themselves of economic and reproductive bondage: "Marriage in most societies transfers to the husband a certain common minimum of rights: almost always an exclusive right to the wife's sexual services, or to the lending of them, certain powers over her person, rights to the produce of her economic activity balanced by economic obligations to her." ([7]:227). What about the reciprocity of sexual access (or the lending of it) and rights over the male 'person'? The fears and hopes of western males are expressed through elision of 'native' lifeways: "...women are always straining to be released." ([7]:230), and ..."she is forever bound to her husband's village." ([7]:232).

There is an apparent conflict between the wishes of the sexes. This conflict is certainly taking place in Western societies, and it may be universal, although the latter possibility cannot be understood from reading the texts of the first decade of our period. These reveal only western latencies, and in their dominance over the field of social anthropology, set the stage for what was to come over the next twenty years.

\section{Discussion}

The articles from 1951-1970 are characterized by a gradual yet distinct shift in organization of assumptions. Although gender as an incipient category of reference makes its first appearance in our final article ([9]), it is enabled to do so by the questioning of many other inherent assumptions within social anthropological reporting.

Edmund Leach's 1961 article (portions of the text date from 1951) begins a partial re-evaluation. While our first axis' marks remain virtually unchanged throughout the second and third decades of our references, that is, word order presenting males in a primary position ([10]:57, [8]:75) native actors as males ([10]:72, [5]:266), egos in kinship diagrams as males ([10]:75 but cf. page 62 where both sexes are represented), and the type face in both text and diagrams ([10]:86) underscoring androcentric categories, other broad categories of paradigmatic quality, or that which actually gives rise to 'paradigms' are slowly fading: "By this I do not mean to argue that women have no part to play in the arrangement of a marriage or that remotely situated kinfolk are ignored..." ([10]:56), began questioning the accuracy of the androcentrism in marriage description, and "But since this kind of ordering of local groups does not, as far as we know, exist, the Murdock version of the Murngin social structure need not be further considered." ([10]:69-70), questioned accuracy of kin models.

Also in Leach, we find other incipient re-evaluative statements: On possible joint authorship of reality with native peoples: "...based on a necessarily very simplified 'model' of any empirical reality. But the 'model' is one which, in effect, the Kachin have constructed themselves." ([10]:85), and the questioning of the accuracy of the social and kin models as fundamental to ethnographic universes: "The description of Kachin society given in the previous section of this essay was the description of a model; I said nothing about culture or language, population or geography..." ([10]:91 and later on 95), and perhaps most important as a clue for us, the qualification of formerly dogmatic and one-sided statements about relations between the 'sexes' in 'native' life: "Yet equally there are cases where the wife's group retain the offspring and 'buy' the sexual services of the husband from the husband's group." ([10]:101:note1).

This tone of questioning assumptions born of a much earlier period is continued by other authors: "Both definitions are clearly based upon the institutions of our own society, where prohibitions on intercourse, like prohibitions on marriage, are bilaterally organized within the limits of kin. But 
are these necessarily adequate for the analysis of nonEuropean societies?" ([8]:290), and "Likeanthropologists, sociologists and psychologists dealing with our own society have patently failed to realize the ethnocentric nature of their categories." ([8]:80). Note that ethnocentrism is broached, but not androcentrism. Note also that really fundamental working concepts such as that of 'society' are not questioned. Dumont continues this critique: "The marriage regulation. rests only on undue generalization of our commonsense categories." ([1]:183), and "The system analyzed hitherto is no more than an abstract frame of reference..." ([1]:187).

Yet there is still ample evidence of the subtle and constricting forms of trace that bely the androcentrism of the period, and thus of the period's mouthpieces. In Leach ([10]:100), we have a table which, although presents women in a different category from labor, consumer goods, territorial rights and so on, allows the hierarchies of property relation to continue unabated - women as most valuable and sought after property, females coveted, controlled, and celebrated simultaneously. Leach changes his theoretical approach over the decade, moving from the comparative from the date of the original essay from which the table comes, to the generalizing ([10]:5), yet this methodological movement does not allow for the intrusion of new categories of subject or object, merely the clearing of the ground in which they might appear by the questioning of those previously entrenched.

Even so, many new methodological concepts do appear as a result of movement away from the 'structural- functionalists' dogmatisms. In Fortes ([5]:263) we find descent categorized in jural-legal language, and that of ritual symbolism ([5]:270). There is also a growing recognizance of American anthropology, in quoting or using student's work from that tradition ([5]:270, [6]). People become loci of rights and obligations, the property relation between males and females is divided into reproductive and pleasure/productive powers ([9]:107ff., [5]:272, [13]), and quantitative methods examining precisely defined variables are touted ([13]:260). The cross-cousin marriage concept is questioned as a misnomer ([1]:24-5, [12]:200). Leach ([10]:1) recognizes that "...the personal involvement of the anthropologist in his work is reflected in what he produces." Ironically, where one level of naivety is pushed back, another remains just as strong. The newly aware anthropologists are still almost all male.

Leach continues to shift from the naivety of 'butterfly collecting' comparative analyses to the mathematical and generalizing naiveties of his rethinking. He feels that math and logic are somehow less value-laden than previous concepts used to drive methodologies. In fact, he has merely pushed the Eurocentrism back into a non-ethnological realm, therefore begging the question which asks 'How do we adequately describe a consciousness of which we are not a part?'. Instead he says "We need to understand that the establishment of classifying categories is never more than a temporary ad hoc expedient. Most such categories have ceased to serve any useful purpose long before they achieve the distinction of appearing in print." ([10]:26). Since Leach merely changes categories on us, we might say, as 'gender' was not one that appeared in his new set, that the 'position' of 'gender' in written and spoken discourse was not a privileged or serious one. It may indeed have been extant without leaving us a discursive trace. Other concepts keep becoming serious instead. Even so, these concepts serve to shift the focus away from pure description of ethnographic 'facts' and models, the concrete native evidences giving the abstract modeling of the investigator, to the examination of what methods might serve to advance explication of these 'facts'. Ultimately, it is this shift, which first appears so minor, but which steadily grows and is exemplified in Leach's contradictory naivety (for example, compare his comments on personal involvement on the first and last page of the introduction to Rethinking Anthropology in 1961, and the parallel with Maybury-Lewis' ([12]:222) 'emic' and 'etic' that continued the archaic concrete vs. abstract dichotomy that prevailed in earlier anthropology) that allows the necessary distance to occur, which in turn allows for 'gender' as an anthropological object and subject to appear.

Before this was to happen, many of the marks outlined in detail for the first decade re-appear. It is not necessary to quote them again in detail, some are exactly the same, others new variations. It is the marks that give us our second axis that again are of more import, but a few examples of both 'types' can be given: "The tying of the a string...round the bride's neck has certainly a sacramental value, especially for the bride." ([1]:192). Here the 'symbolic' content of property, chattel and possession have become sacred, reflecting a latency for such a state of affairs as was extant in ancestral Europe. "On the whole, the final result is a gift which accompanies the gift of the girl." ([1]:196). Perhaps both ethnographic and observant culture wish for the same controlled celebration - and celebrated control - over women. "Other things being equal, a wife will reside with her husband if he, or whoever has jural authority over him, has the unrestricted rights over her sexual and economic services and reproductive powers..." ([6]:88). What are the 'other things', in this case?

Again, constraints that are seen as negative are attributed to the female side, whether purely due to physiology, or something perhaps more metaphysical: "The biological limiting factor here is the duration of the wife's fertility." ([6]:69), and "...the witch is presumed to be an unconscious and involuntary agent; she brings disaster upon her husband..." ([10]:22). Later on ([10]:23) it is implicit that women in general should not have the authority to consciously attack others, and if they do, it is either due to a mystical unconscious attack, or is treated as a great disaster and evil, the seat of which remains in women. Yet this dangerous foment may be circumvented by a property relation: "We can look upon [marriage payments] as a ritual payment which releases the mystical sexual powers of the girl." ([13]:253). If 'other things are not equal', the danger still exists: "This he relates to the lack of traditional restraints, the 
town, the idleness of the women making them 'all the more ready for sexual adventures'..." ([18], paraphrased in [13]:258). Are men not ready for such license? Or perhaps they are entitled to it, and as such it does not present a danger, let alone a license?

When a new analytic is presented, as in Maybury-Lewis ([12]), the first axis marks are still the same: "To sum up, then, the approach to prescriptive marriage systems here outlined takes as its point of departure the rule in certain societies that a man's wife must belong to a specific relationship category." ([12]:205-6). Ego continues to be male, because the events that are being described revolve around a 'him', rather than a 'her', the latter is merely a necessary and secondary part of the formula. Although Maybury-Lewis wishes to believe that "...there are fundamental theoretical and methodological issues at stake. [and that] a man who is tired of issues such as these is tired of social anthropology." ([12]:222-3), we can see a gradual shift, manifested as boredom, away from kinship and social organization. Note that women were presumed still interested in these issues, or never interested, or perhaps were just a distraction for the males.

Or in the pettiness of marking of 'sex': "I shall likewise criticize the work of Hodson, Mrs Seligman, Granet, LeviStrauss and others." ([10]:63 - 'Mrs' appears eleven times, ten for Seligman, who interestingly is not given her 'title' in a quote reference on page 66 , and once for a Wouden, as well as 'Miss' three times for a certain Wedgewood). By the time of Goody's ([8]) article, Seligman becomes "Brenda Seligman" ([8]:76, twice), which takes place also in the privileged midst of esteemed anthropologists and figures such as Freud and Parsons. Women cannot be colleagues, only students or interested by-standers. Witness Leach's "Dr. Kathleen Gough" ([10]:10), where the professional title is given its due, but the fact of femaleness must still be distinguished. This is a 'reverse' mark, but betrays the same androcentrism, because it denies equality or anonymity to the researcher.

The 'Euro-Analogy' continues to surface - on the proper and Victorian socialization of children: "Moral responsibility is demanded of both sexes. They have to learn to control their affective attitudes...they are now permitted to enter into relationships which involve adult sexuality for procreative ends, as opposed to childish sexuality for pleasurable ends." ([6]:93-4). Sex is sanctioned only in the family, for the purposes of reproduction. This is its demonstration of maturity. In Witherspoon ([19]:56-8) the analogies with the Euro-American mythos regarding the characterization of women as less intelligent, weaker, inherently more evil and lusty vessels is taken to an extreme with the translation of Navajo myths: "As years went by, the women became weaker; they needed the men's strength to produce food, and they became maddened by desire. As a result of self-abuse they gave birth to monsters that destroyed men. [by contrast] The men too practiced perversion, but from their excesses no evil survived." ([19]:57). Given the era of growing female emancipation, women using precisely the same statements and arguments of self-sufficiency found in the Navajo myths, the cautionary tale against such reform minded females is all too convenient. Perhaps white culture is suffering from a pathology that the Navajo undertook to resolve in bygone ages? Witherspoon's analysis is fraught with the naivety of thinking that the anthropologist can remove personal bias from his interpretation of an ethnographic culture ([19]:56), allowing him the necessary innocence in translation. In fact, there may be a metaphor within Witherspoon's text that links the transferring of the 'motherhood powers' of life from ancestor to successor, although still controlled ultimately by the male, with the allegorically transferred perversions and evil from male to female in the myth cycle. Both earthly and metaphysical powers, good and evil, may 'on the ground' reside within men.

The type of power infused into the female in Witherspoon is facile. It can be contrasted with the incipient power alluded to in Gough ([9]), the final article in our set, and the one that seems to close out the dominance of an era in anthropology.

A few quotes will suffice to show the shift in language present: "A female legal marital partner holds these rights in the same manner as a male..." ([9]:107), "It is safe to assume from this that, in Nuerland as a whole, just under half the women of childbearing age are under the legal guardianship of no man, this surely has important implications for the 'strength of the agnatic principle'." ([9]:109), and, "...by separating the rights in a woman as sexual partner and domestic worker from the rights in her as genetrix, affords a certain personal autonomy to women..." ([9]:111), "...the analysis is somewhat distorted by being presented largely from the point of view of men. Pages are devoted to the relationships between male kinsmen, paragraphs to those between men and women, and a few lines only to relationships among women." ([9]:114). This final quote, however cautious, is extraordinary in light of what we have examined previously. At the end of our three decades of mostly British social anthropology, we have reached a point where all of a sudden, it matters if the investigator is male or female. The anthropology of gender has been born.

\section{Conclusions}

Why is there no such thing as 'gender' as we understand it within this set of texts? Gender is never given as a reason for anything: "Physical environment, way of livelihood, mode of distribution, poor communications, simple economy etc, to some extent explain the incidence of political cleavage..." ([3]:284), "...there are more intimate relations between their members in the dry season. The radius of effective kinship is greater in the dry season than in the wet." ([4]:363), "...it is exchange, always exchange, that emerges as the fundamental and common basis of all modalities of the institution of marriage." ([11]:48). Women here are not a 'gender', they are property to satisfy property relations amongst men. Men are also not a 'gender', they are physiocratic proprietors and exchangers. In fact if women were anything at all, they were "...valuables par excellence from both the biological and the 
social points of view, without which life is impossible..." ([11]:51).

If neither male nor female are engendered, if one is taken as object of study, the other as given, if one is both subject and object, observer and observed, and the other merely observed, there exists no space into which a meaningful, spoken, and serious distance can occur. The distance and difference between male and female was not 'unsaid', it just could not have been said. Perhaps after singing it for a while, it is now time that it be rendered unto a new and transcendental silence.

\section{REFERENCES}

[1] Dumont, L. 'The Marriage Alliance', in Kinship, J. Goody ed. Penguin Books, Ltd. London. (1971). Pages 183-197. 1957

[2] Evans-Pritchard, E.E. The Nuer. Oxford University Press. 1940

[3] Evans-Pritchard, E.E. 'The Nuer of the Southern Sudan', in African Political Systems. Meyer Fortes and A.R. Radcliffe-Brown, eds. Oxford University Press. Pages 272-296. $1940 \mathrm{~b}$

[4] Evans-Pritchard, E.E. 'Kinship and Local Community Among the Nuer', in African Systems of Kinship and Marriage. A.R. Radcliffe-Brown and Daryll Forde, eds. Oxford University Press. Pages 360-392. 1950

[5] Fortes, Meyer 'The Structure of Unilineal Descent Groups', in Kinship. J. Goody, ed. Penguin Books, Ltd. (1971). Pages 263-273. 1953

[6] Fortes, Meyer 'The Developmental Cycle in Domestic Groups', in Kinship. J. Goody, ed. Penguin Books, Ltd. (1971). Pages 85-98. 195

[7] Gluckman, Max 'Marriage Payments and Social Structure Among the Lozi and Zulu', in Kinship. J. Goody, ed. Penguin Books, Ltd. (1971). Pages 227-245. 1950
[8] Goody, Jack 'A Comparative Approach to Incest and Adultery', in British Journal of Sociology, volume 7, 1956. Pages 286-305. 1956

[9] Gough, Kathleen 'Nuer Kinship: A Re-examination', in The Translation of Culture. T.O. Beidelman, ed. Tavistock. Pages 79-121. 1971

[10] Leach, Edmund Rethinking Anthropology. The Athlone Press, London. 1961

[11] Levi-Strauss, Claude 'Principles of Kinship', in Kinship. J. Goody, ed. Penguin Books, Ltd. (1971). Pages 47-61. 1949

[12] Maybury-Lewis, David 'Prescriptive Marriage Systems', in Kinship. J. Goody, ed. Penguin Books, Ltd. (1971). Pages 199-224. 1965

[13] Mitchell, J.C. 'Social Change and the Stability of Marriage in Northern Rhodesia', in Kinship. J. Goody, ed. Penguin Books, Ltd. (1971). Pages 248-260. 1962

[14] Radcliffe-Brown, A.R. 'Introduction', in African Systems of Kinship and Marriage. A.R. Radcliffe-Brown and Daryll Forde, eds. Oxford University Press. Pages 1-85. 1950

[15] Richards, Audrey I. 'The Political System of the Bemba Tribe', in African Political Systems. Meyer Fortes and A.R. Radcliffe-Brown, eds. Oxford University Press. Pages 83-120. 1940

[16] Richards, Audrey I. 'Some Types of Family Structure Among the Central Bantu', in African Systems of Kinship and Marriage. A.R. Radcliffe-Brown and Daryll Forde, eds. Oxford University Press. Pages 207-251. 1950

[17] Richards, Audrey I 'Matrilineal Systems', in Kinship. J. Goody, ed. Penguin Books, Ltd. (1971). Pages 277-289. 1950

[18] Wilson, G. An Essay on the Economics of Detribalization in Northern Rhodesia. Rhodes-Livingstone Paper, no. 6. 1941

[19] Witherspoon, Gary 'A New Look at Navajo Social Organization', in American Anthropologist, 72. Pages 55-65.1970 